\title{
Margins in DCIS: Does Residual Disease Provide an Answer?
}

\author{
Monica Morrow, MD and Kimberly J. Van Zee, MS, MD () \\ Breast Service, Department of Surgery, Memorial Sloan Kettering Cancer Center, New York, NY
}

Minimizing tumor burden has been the guiding principle for breast cancer surgery since the days of Halsted. The recognition that clinically and radiographically unicentric carcinoma was frequently multifocal on detailed histologic examination, coupled with studies of sham lumpectomies demonstrating that $26-38 \%$ of patients had residual carcinoma in mastectomy specimens, led many to conclude that mastectomy was the only appropriate management strategy for breast cancer. ${ }^{1,2}$ Fortunately, multiple, prospective, randomized trials disproved this notion, but our fixation on local disease burden remains and, in the era of breast-conserving surgery (BCS), is now focused on defining the margin width that minimizes the likelihood of residual cancer. Yet, we have known for more than 3 decades, since the first publication of the National Surgical Adjuvant Breast and Bowel Project (NSABP) B06 trial, that radiation is quite effective in treating residual disease in the breast, as that seminal trial showed that in-breast recurrence with lumpectomy alone was high, whereas with lumpectomy followed by radiation, the rate was similar to that of mastectomy. ${ }^{3}$ In thinking about margins, it is worth remembering that the ultimate endpoint is local recurrence, not residual cancer. There is no negative margin width short of a mastectomy that guarantees the absence of cancer in the breast, and even a mastectomy does not guarantee freedom from local recurrence.

In recent years, we have come to understand that biology is a major determinant of local recurrence of invasive cancer. Rates of local recurrence vary based on hormone receptor and HER 2 status, even among the smallest cancers, and after controlling for other factors, rates of local recurrence do not differ significantly based on treatment with BCS with radiation or mastectomy. ${ }^{4-6}$ In addition,

(C) Society of Surgical Oncology 2016

First Received: 23 March 2016;

Published Online: 10 May 2016

M. Morrow, MD

e-mail: morrowm@mskcc.org systemic therapy has a major impact on rates of local recurrence. $^{7}$ These factors, coupled with a meta-analysis demonstrating no benefit for margins more widely clear than no ink on tumor, played a crucial role in the development of the Society of Surgical Oncology (SSO)American Society of Therapeutic Radiation Oncology (ASTRO) consensus guideline for margins in invasive cancer, which endorsed no ink on tumor as the appropriate negative margin width. ${ }^{8,9}$

For ductal carcinoma in situ (DCIS), the situation is different. Biologic features defining the behavior of DCIS remain elusive. Surgeons have assumed that with this noninvasive, nonmetastatic lesion, local treatment is paramount: if we cut enough out, the problem will be solved. Outcome studies after mastectomy for DCIS reporting rates of local recurrence and cause-specific mortality at 20 years of $<2 \%$ appear to support this assumption. ${ }^{10,11}$ Although mortality in patients selected for BCS with or without radiotherapy does not differ from mortality in women selected for mastectomy, rates of local recurrence certainly do. ${ }^{10,11}$ Local recurrence rates are markedly higher with BCS with or without radiotherapy compared with mastectomy. Additionally, local recurrence rates are markedly higher after BCS alone as compared with BCS with radiation-hence, the continuing search for the margin width that will minimize local recurrence.

In this issue of Annals of Surgical Oncology, Merrill and coauthors examine the amount of residual DCIS found in cavity shave margin specimens relative to the width of the margin in the primary lumpectomy. Residual DCIS was present in $88 \%$ of those with positive margins, in $49 \%$ of those with clear margins of $\leq 1 \mathrm{~mm}$, in $63 \%$ of those with margins $>1 \mathrm{~mm}$ but $<2 \mathrm{~mm}$, and in $13 \%$ with margins $\geq 2 \mathrm{~mm}$. The finding of significant amounts of residual disease, even in patients with negative margins, is not surprising. In 1995 Cox et al. examined the likelihood of residual disease in the breast in 599 patients having excisional biopsy and found residual cancer in approximately 
$50 \%$ of cases. ${ }^{12}$ Sabel et al. examined the incidence of residual disease after reexcision for close margins $(\leq 2$ or $3 \mathrm{~mm}$ ) in 130 patients, 31 with DCIS, and found residual disease in $42 \%$ of the DCIS patients and $29 \%$ of those with invasive disease-remarkably similar to the $45 \%$ incidence in DCIS patients and $24 \%$ incidence in invasive patients with positive margins. ${ }^{13}$ These studies are all consistent with the pathologic studies of Holland et al., which demonstrated that $40 \%$ of patients with clinically and radiographically unifocal invasive cancer have microscopic residual disease at a distance $>2 \mathrm{~cm}$ from the index lesion and that this tumor burden is highest in patients with an extensive intraductal component. ${ }^{1}$ While advances in imaging and pathologic assessment of margins have probably reduced the burden of residual disease after resection of DCIS with clear margins, the current incidence is not zero.

The question that remains unanswered is whether a reduction in residual DCIS from $49 \%$ of cases to $13 \%$ of cases as margin width increases from negative, but $<1 \mathrm{~mm}$, to $>2 \mathrm{~mm}$ translates to a meaningful reduction in local recurrence, particularly in patients receiving radiotherapy. The question of margin width in DCIS has never been examined in a randomized trial. The NSABP used the definition of no ink on tumor in its B17 and B24 trials. ${ }^{14}$ The 15-year rates of in-breast recurrence were $35 \%$ in those not receiving radiation therapy and $18 \%$ in those receiving radiation therapy. These are now old studies, and outcomes of DCIS treatment have improved over time. ${ }^{15}$ Van Zee et al. performed a detailed examination of the impact of margin width on local recurrence in 1588 DCIS patients receiving radiotherapy and 1374 patients treated with excision alone. ${ }^{16}$ In the radiotherapy group, the 10year rate of local recurrence for those with negative margins $\leq 2 \mathrm{~mm}$ in size was $12 \%$ compared with $10 \%$ for those with margins $>1 \mathrm{~cm}$. In multivariate analysis, margin width was not a significant predictor of recurrence among those receiving radiation, even after adjusting for multiple clinical and pathologic variables. In contrast, in patients not receiving radiotherapy, 10-year local recurrence rates decreased from $27 \%$ in those with negative margins $\leq 2 \mathrm{~mm}$ in size to $16 \%$ in the $>1-\mathrm{cm}$ group, and margin width was a highly significant $(p<0.0001)$ predictor of local recurrence in multivariate analysis. While it seems intuitively obvious that removal of more DCIS would be particularly important in those not receiving radiotherapy, even this literature is not consistent. In the Eastern Cooperative Oncology Group (ECOG) E5194 trial of excision alone for DCIS, 3-mm margins were mandated by the protocol. An analysis of wider negative margins $(<5 \mathrm{~mm}$ vs. 5-9 $\mathrm{mm}$ and $\geq 10 \mathrm{~mm}$ ) found no association with the 12 -year rate of in-breast recurrence. ${ }^{17}$
The SSO-ASTRO guideline on margins in invasive cancer clearly states that it should not be assumed to be appropriate for patients with DCIS. ${ }^{9}$ Recognizing the substantial variation in surgeons' attitudes toward what constitutes an adequate negative margin in DCIS, ${ }^{18}$ the SSO, ASTRO, and the American Society of Clinical Oncology (ASCO) co-sponsored a consensus panel on margins in DCIS in November 2015, which included a new meta-analysis of 8651 DCIS patients reported in 20 studies, as well as a review of other published literature in its evidence base. While awaiting publication of this information, clinicians should bear in mind that multiple factors influence the risk of local recurrence in patients with DCIS and that excellent long-term outcomes have been reported for DCIS treated with excision to minimal negative margin widths and radiotherapy. Measurement of margins is not an exact science, and routinely subjecting patients to mastectomy to obtain an arbitrary negative margin width beyond no ink on tumor, in the absence of other factors that increase the risk of local recurrence, is not good practice. Should the meta-analysis sponsored by the SSO-ASTROASCO DCIS margins consensus conference find that a negative margin width of at least $2 \mathrm{~mm}$ is associated with lower recurrence rates, it is likely that the study reported by Merrill et al. will help to explain why.

\section{REFERENCES}

1. Holland R, Connolly JL, Gelman R, Mravunac M, Hendriks JH, Verbeek AL, et al. The presence of an extensive intraductal component following a limited excision correlates with prominent residual disease in the remainder of the breast. J Clin Oncol. 1990;8(1):113-8.

2. Rosen PP, Fracchia AA, Urban JA, Schottenfeld D, Robbins GF. "Residual" mammary carcinoma following simulated partial mastectomy. Cancer. 1975;35(3):739-47.

3. Fisher B, Bauer M, Margolese R, Poisson R, Pilch Y, Redmond $\mathrm{C}$, et al. Five-year results of a randomized clinical trial comparing total mastectomy and segmental mastectomy with or without radiation in the treatment of breast cancer. $N$ Engl J Med. 1985;312(11):665-73.

4. Cancello G, Maisonneuve P, Rotmensz N, Viale G, Mastropasqua MG, Pruneri G, et al. Prognosis in women with small (T1mic,T1a,T1b) node-negative operable breast cancer by immunohistochemically selected subtypes. Breast Cancer Res Treat. 2011;127(3):713-20.

5. Abdulkarim BS, Cuartero J, Hanson J, Deschenes J, Lesniak D, Sabri S. Increased risk of locoregional recurrence for women with T1-2N0 triple-negative breast cancer treated with modified radical mastectomy without adjuvant radiation therapy compared with breast-conserving therapy. J Clin Oncol. 2011;29(21):2852-8.

6. Zumsteg ZS, Morrow M, Arnold B, Zheng J, Zhang Z, Robson $\mathrm{M}$, et al. Breast-conserving therapy achieves locoregional outcomes comparable to mastectomy in women with T1-2N0 triplenegative breast cancer. Ann Surg Oncol. 2013;20(11):3469-76.

7. Bouganim N, Tsvetkova E, Clemons M, Amir E. Evolution of sites of recurrence after early breast cancer over the last 20 years: implications for patient care and future research. Breast Cancer Res Treat. 2013;139(2):603-6. 
8. Houssami N, Macaskill P, Marinovich ML, Morrow M. The association of surgical margins and local recurrence in women with early-stage invasive breast cancer treated with breast-conserving therapy: a meta-analysis. Ann Surg Oncol. 2014;21(3):717-30.

9. Moran MS, Schnitt SJ, Giuliano AE, Harris JR, Khan SA, Horton $\mathrm{J}$, et al. Society of Surgical Oncology-American Society for Radiation Oncology consensus guideline on margins for breastconserving surgery with whole-breast irradiation in stages I and II invasive breast cancer. Ann Surg Oncol. 2014;21(3):704-16.

10. Narod SA. Treatment and Long-Term Risks for Patients With a Diagnosis of Ductal Carcinoma In Situ-Reply. JAMA Oncol. 2016;2(3):400-1.

11. Worni M, Akushevich I, Greenup R, Sarma D, Ryser MD, Myers ER, et al. Trends in treatment patterns and outcomes for ductal carcinoma in situ. J Natl Cancer Inst. 2015;107(12):djv263.

12. Cox CE, Reintgen DS, Nicosia SV, Ku NN, Baekey P, Carey LC. Analysis of residual cancer after diagnostic breast biopsy: an argument for fine-needle aspiration cytology. Ann Surg Oncol. 1995;2(3):201-6.

13. Sabel MS, Rogers K, Griffith K, Jagsi R, Kleer CG, Diehl KA, et al. Residual disease after re-excision lumpectomy for close margins. J Surg Oncol. 2009;99(2):99-103.
14. Wapnir IL, Dignam JJ, Fisher B, Mamounas EP, Anderson SJ, Julian TB, et al. Long-term outcomes of invasive ipsilateral breast tumor recurrences after lumpectomy in NSABP B-17 and B-24 randomized clinical trials for DCIS. J Natl Cancer Inst. 2011;103(6):478-88.

15. Subhedar P, Olcese C, Patil S, Morrow M, Van Zee KJ. Decreasing recurrence rates for ductal carcinoma in situ: analysis of 2996 women treated with breast-conserving surgery over 30 years. Ann Surg Oncol. 2015;22(10):3273-81.

16. Van Zee KJ, Subhedar P, Olcese C, Patil S, Morrow M. Relationship between margin width and recurrence of ductal carcinoma in situ: analysis of 2996 women treated with breastconserving surgery for 30 years. Ann Surg. 2015;262(4):623-31.

17. Solin LJ, Gray R, Hughes LL, Wood WC, Lowen MA, Badve SS, et al. Surgical excision without radiation for ductal carcinoma in situ of the breast: 12-year results from the ECOG-ACRIN E5194 study. J Clin Oncol. 2015;33(33):3938-44.

18. Azu M, Abrahamse P, Katz SJ, Jagsi R, Morrow M. What is an adequate margin for breast-conserving surgery? Surgeon attitudes and correlates. Ann Surg Oncol. 2010;17(2):558-63. 